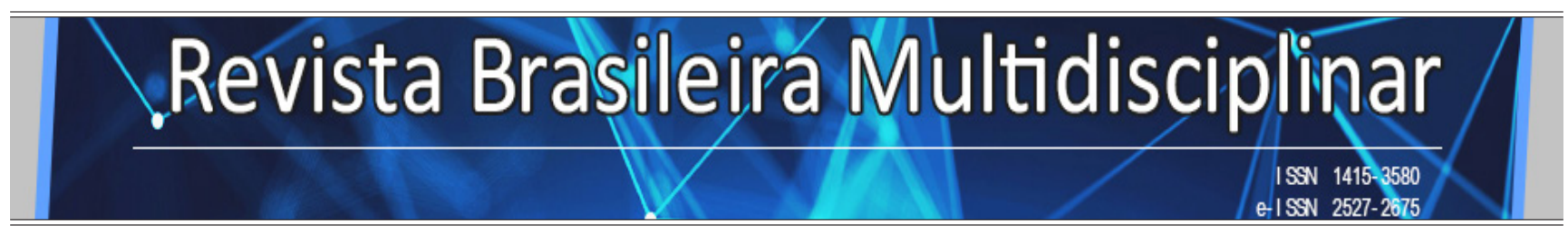

http://revistarebram.com/index.php/revistauniara

\title{
BALANÇO E PERSPECTIVAS DA EVOLUÇÃo DO EMPREgO INDUSTRIAL BAIANO FORMAL (2004/2014)
}

José Edigle Alcantara Moura*; Maria Jeanne Gonzaga de Paiva**.

${ }^{*}$ Mestrando em Economia Rural pela Universidade Federal do Ceará (UFC); ${ }^{*}$ Professor Adjunto do Departamento de Economia da URCA.

*Autor para correspondência e-mail: genur@yahoo.com.br

\section{Palavras-chave}

Região Metropolitana de Salvador Interior do Estado da Bahia Indústria

Emprego Formal

\section{KEYWORDS}

Salvador Metropolitan Area Bahia Countryside

Formal Employment

\section{RESUMO}

O artigo tem por objetivo fazer uma análise do emprego formal industrial baiano no período de 2004 e 2014, desagregando a unidade federativa em Região Metropolitana de Salvador (RMS) e Interior do Estado. Para tanto, são estudadas as seguintes variáveis: número de estabelecimentos industriais, porte da indústria, empregos formais por setor, ramo de atividade, sexo, grau de instrução, tempo de serviço e faixa de remuneração. Os dados utilizados são da Relação Anual de Informações Sociais do Ministério do Trabalho e Emprego. Os principais resultados mostram ampliação das plantas industriais, principalmente no Interior do Estado. No que tange ao perfil socioeconômico e sociodemográfico existe uma predominância da mão-de-obra masculina alocada predominantemente em empreendimentos de médio e grande porte com menos de 01 ano, no tempo de serviço com ampliação da escolaridade dos ocupados formais e contrariamente ao esperado redução do salário médio mediante empobrecimento ao longo dos anos do estoque de empregados.

\section{Abstract}

BALANCE AND PROSPECTS OF THE DEVELOPMENT OF FORMAL INDUSTRIAL EMPLOYMENT IN BAHIA (2004/2014)

This article aims at analyzing formal employment in Bahia from 2004 to 2014, dividing the Federative Union into Salvador Metropolitan Area (RMS) and the State Countryside. Therefore, the following variables are studied: number of industrial establishments, formal employments in the processing industry, occupation per sex, education level, length of service and income level. Data were obtained from the Social Information Annual Report provided by the Ministry of Labor and Employment. The main results show a growth of industrial plants, mainly in the state countryside. With regards to the socioeconomic and sociodemographic profiles, there is a predominance of male manpower allocated mainly in medium and large undertakings with a length of service of at least 01 year and a decrease in the schooling level of formal employees. Contrary to what was expected, a reduction in the average wage due to the impoverishment of employees throughout the years was verified. 


\section{INTRODUÇão}

A dinâmica econômica estruturalista propôs aos trabalhos desenvolvidos pela Comissão Econômica para a América Latina (CEPAL), uma série de implicações em termos de política econômica que procurou a inserção das economias latino-americanas em uma ótica baseada no desenvolvimentismo como forma de encarar os pontos de estrangulamento da economia brasileira, uma vez que, a esta superação baseava antes de tudo na industrialização por ação ativa do Estado (CANO, 2011).

Dentro desse contexto, a germinação da industrialização da Região Nordeste foi constituída mediante o Grupo de Trabalho para o Desenvolvimento do Nordeste (GTDN), no qual diagnosticou que os gargalos econômicos, sociais e demográficos dessa Região não vinham de um determinismo histórico da condição de subdesenvolvimento, mas da necessidade de um ajuste estrutural para uma divisão regional do trabalho a fim de integrar os capitais produtivos do Nordeste ao eixo Centro-Sul (CANO, 1997).

Até os anos 1950, a economia nordestina se acomodava às transformações da economia nacional. A partir de 1960, com a transferência dos capitais produtivos para a região mediante ação do Estado, inicia-se uma fase de considerável dinamismo com o objetivo de industrializar o Nordeste através da Superintendência de Desenvolvimento do Nordeste (SUDENE) iniciando a implantação de projetos em atividades industriais antes inexistentes além de promover a modernização de atividades em trabalho/ intensivas, a exemplo da indústria têxtil.

Ademais, as grandes transformações do Nordeste brasileiro ocorreram principalmente na segunda metade da década de 1970, como consequência das ações do II Plano Nacional de Desenvolvimento (II PND) que objetivava a redução das disparidades através da consolidação de uma economia moderna, mediante criação de novos setores, adaptação de novas tecnologias e ajustamento às novas realidades da economia mundial, mediante esforço de integração nacional e estratégia de desenvolvimento regional.

No entanto, a partir da década de 1990, com o esvaziamento das políticas de desenvolvimento nacional, redimensionamento do papel do Estado na economia, reestruturação da produção e dos novos métodos de organização do trabalho, percebe-se um fenômeno de indústrias do Sul/Sudeste migrarem para o Nordeste brasileiro (ARAÚJO, 2017; PACHECO, 1998), a exemplo da Bahia (PEREIRA, 2008; CAVALCANTE, 2004), em busca de incentivos fiscais, mão-de-obra barata e abundante, sindicatos pouco combativos e redução, do custo de transporte através da proximidade com o mercado consumidor internacional (ARRAIS et al., 2008).

Dessa forma, a hipótese deste trabalho é que o Estado da Bahia aumentou a estrutura produtiva industrial, representada pelo quantum de estabelecimentos, no entanto à qualidade dos empregos formais foram marcados pela desestruturação/precarização do mercado de trabalho. A problematização a que esta hipótese busca responder indaga sobre: quais as formas de resposta do mercado de trabalho industrial baiano frente à sedimentação mais nítida do modo de regulação neoliberal?

Dessa forma, este trabalho pretende preencher as lacunas em relação à literatura, mediante análise do emprego formal industrial baiano desagregado da Região Metropolitana de Salvador (RMS) ${ }^{1}$. Essa decomposição geográfica permite em primeiro momento fazer uma comparação entre essas duas áreas, em segundo estágio, instrumentaliza o setor privado à alocação mais eficiente dos investimentos industriais no território baiano, uma vez que, segundo Brandão (2013) é uma unidade federativa marcada por elevada heterogeneidade estrutural.

Diante do exposto, o objetivo central deste artigo é analisar o emprego formal industrial do Estado da Bahia no período de 2004 e 2014. Além do mais, compara-se o perfil socioeconômico e sociodemográfico

\footnotetext{
${ }^{1}$ Os municípios que compõem a Região Metropolitana de Salvador são: Camaçari, Candeias, Dias d’Ávila, Itaparica, Lauro de Freitas, Madre de Deus, Mata de São João, Pajuca, Salvador, São Francisco do Conde, São Sebastião de Passé, Simões Filho e Vera Cruz.
} 
(sexo, grau de instrução, tempo de serviço e rendimento) dos trabalhadores empregados na indústria formal.

Para atingir o objetivo proposto, o artigo encontra-se, assim estruturado: além desta introdução, a segunda seção aborda uma breve revisão de literatura sobre o mercado de trabalho formal nordestino em diferentes áreas; em seguida, na terceira seção, tecem-se os procedimentos metodológicos necessários ao desenvolvimento do trabalho e na quarta seção, apresentam-se os resultados e discussão.

\section{MERCADO DE TRABALHO FORMAL INDUSTRIAL NORDESTINO EM DIFERENTES ÁREAS: BREVES EVIDÊNCIAS}

A dinâmica do emprego formal industrial tem sido frequentemente utilizada em pesquisas relacionadas ao panorama do mercado de trabalho associada a questões regionais, como são os casos, por exemplo, dos estudos, em âmbito regional desenvolvido por Arrais et al. (2008). Em termos estaduais, destacam-se os elaborados por Silva Filho e Queiroz (2009) e Pereira (2008). Para as regiões metropolitanas, Fortaleza, Recife e Salvador, assim como suas unidades federativas, respectivamente, destaca-se o trabalho de Brandão (2013). Considerando estudos destinados a nível municipal, ressalta-se o desenvolvido por Barbosa (2013).

Segundo Arrais et al (2008), utilizando-se, para análise empírica, o banco de dados da Relação Anual de Informações Sociais (RAIS), mostraram o significativo número de indústrias instaladas no Nordeste, com predominância de trabalhadores alocados na indústria alimentícia, têxtil e calçadista, enquanto no Sudeste, o emprego é bem distribuído entre os setores da indústria. Em ambas as regiões, a rotatividade é elevada, sendo mais intensa para o Nordeste, predominando a mão-de-obra masculina na faixa etária de 30 a 39 anos. No Nordeste, em 2004, parcela majoritária dos ocupados tinha até o ensino fundamental incompleto e no Sudeste até o ensino superior incompleto.

Para Silva Filho e Queiroz (2009), apesar da melhoria no nível de instrução dos trabalhadores cearenses alocados no setor industrial, aproximadamente 50\% da mão-de-obra da Região Metropolitana de Fortaleza (RMF), e do interior, não têm o ensino fundamental completo. A rotatividade é elevada, sendo mais intensa para o interior, dado que $1 / 3$ dos trabalhadores permanece empregado por menos de 1 ano, com $82,90 \%$, na RMF, e 90,88\%, no interior, ganhando até 2 salários.

Considerando os estados do Ceará e Bahia, Pereira (2008) fez um comparativo do emprego formal industrial nas unidades federativas supracitadas. Os principais resultados evidenciaram a intensa a seletividade por sexo, idade, escolaridade, além da elevada rotatividade e baixos salários em ambos os estados, sendo a precarização mais acentuada para o Ceará, notadamente na indústria calçadista que registrou 86,09\% dos ocupados alocados por menos de 1 ano de tempo de serviço, no ano de 2006.

De acordo com Brandão (2013), a participação do emprego industrial baiano aumenta de 19,81\% em 1995 para 23,58\% em 2010. Ademais, o setor com maior representatividade no Estado, foi o calçadista, com elevação de 1,58\% para 31,32\% no recorte temporal estudado. Tal resultado decorre da política fiscal praticada pela Bahia, que atraiu segmentos industriais intensivos em trabalho. Porém, outros setores apresentaram aumento do emprego industrial na Bahia, a exemplo do ramo de material elétrico e de comunicações que saltou sua participação relativa de 9,33\% para 36,24\% no período de 1995 e 2010.

Barbosa (2013) afirma que as cidades de Juazeiro do Norte, Crato e Sobral no interior do Ceará ampliaram o estoque de empregos formais no setor industrial, que passou de 6.596 em 1990 para 44.660 empregos formais em 2010, apresentando uma taxa de crescimento de 532\%. Ainda, quanto ao nível salarial, a década de 1990 registrou menores níveis. Nos anos 2000, houve ganhos em todas as cidades. Entretanto ao final do período estudado, essa amostra de cidades cearenses continuou apresentando níveis 
salariais relativamente baixos. Nota-se, a partir dos estudos elencados, que essa questão tem ocupado espaço nas agendas de pesquisa, evidenciando o emprego formal industrial.

\section{Procedimentos metodológicos}

\section{ÁREA DE ESTUDO}

O estado da Bahia é o mais populoso da região Nordeste. Situa-se ao sul dessa região e faz divisa com oito estados: Alagoas, Sergipe, Pernambuco e Piauí ao norte, Minas Gerais e Espírito Santo ao sul, Goiás e Tocantins a Oeste. Ao leste, faz divisa com o Oceano Atlântico. Logo, a Bahia é o estado que mais faz divisa com outras unidades da federação. Tem uma área geográfica de $564.692,669 \mathrm{~km}^{2}$, o que corresponde a 35,24\% da Região Nordeste e a 6,63\% do total do Brasil. Segundo os dados demográficos de 2010, esse estado possui um total de 14.016.906 habitantes distribuídos em uma densidade demográfica de 24,82 hab. $/ \mathrm{km}^{2}$ e taxa de urbanização de $72,07 \%$ da área total ocupada (IBGE, 2010).

\section{CARACTERIZAÇÃo dos métodos analíticos}

Para atender o objetivo proposto nesse trabalho, foram adotados os métodos, descritivo e explicativo. O primeiro descreve as características do tema proposto, a partir da análise do emprego formal industrial baiano, mediante revisão da literatura.

Segundo Gil (2010), a abordagem metodológica explicativa tem como objetivo complementar o método explicativo, por meio da análise das estatísticas que levam à obtenção dos resultados, servindo como base de sustentação dos conhecimentos expostos.

Dessa maneira, foram utilizados o estudo e tabulação das principais variáveis concernentes ao perfil socioeconômico do trabalhador do setor industrial baiano.

\section{BASE DE DADOS E DESCRIÇÃo dAS VARIÁVEIS}

Os dados são oriundos da Relação Anual de Informações Sociais (RAIS) do Ministério do Trabalho e Emprego (MTE), referentes ao período cronológico que compreende os anos de 2004 e 2014. Apesar das limitações, uma vez que cobre apenas o mercado de trabalho formal, capta de forma eficiente as características socioeconômicas dos trabalhadores com vínculo formal e regulamentado (celetista, estatutário, temporário e avulso regulamentado).

A referida base apresenta a vantagem de ter abrangência nacional, inclusive municipal, e com imensa dispersão de variáveis que designam o perfil socioeconômico dos trabalhadores, captando a evolução, oscilação e/ou redução dos postos formais de trabalho no decorrer do tempo, uma vez que possui periodicidade anual.

Foi utilizado um total de oito variáveis: número de estabelecimentos, número de empregos formais por setores, ramo de atividade econômica, tamanho da indústria, sexo dos trabalhadores, nível de escolaridade, tempo de serviço e faixa de remuneração.

A escolha das variáveis selecionadas para este estudo teve por base os trabalhos que abordam o perfil socioeconômico do trabalhador formal, entre eles: Pereira (2016); Brandão (2013); Barbosa (2013) e Arrais et al (2008), dentre outros.

\section{RESUlTADOS E DISCUSSÃo}

NúMERO DE ESTABELECIMENTOS INDUSTRIAIS NO ESTADO DA BAHIA

Segundo os dados da Relação Anual de Informações Sociais (RAIS) se destaca na tabela 01, o crescimento nominal de indústrias formais instaladas entre 2004 e 2014, com destaque para o Interior do 
Estado baiano, que passou de 5.405 indústrias em 2004 para 9.135 unidades produtivas em 2014, sofrendo variação ao longo do período em estudo de $69,01 \%$ contra variação de $60,59 \%$ na RMS, que passou de 2.598 indústrias em 2004 para 4.172 unidades em 2014.

Tabela 01 - Número de estabelecimentos industriais na Região Metropolitana de Salvador e Interior do Estado-BA, 2004/2014.

\begin{tabular}{c|c|c|c|c|c}
\hline \multirow{2}{*}{ Região } & \multicolumn{2}{|c|}{$\mathbf{2 0 0 4}$} & \multicolumn{2}{|c|}{$\mathbf{2 0 1 4}$} & \multirow{2}{*}{\begin{tabular}{c} 
Variação(\%) \\
\cline { 2 - 5 }
\end{tabular}} \\
\cline { 2 - 5 } & Abs & $\mathbf{( \% )}$ & Abs & (\%) & \\
\hline RMS & 2598 & 32,46 & 4172 & 31,35 & 60,59 \\
INTERIOR & 5405 & 67,54 & 9135 & 68,65 & 69,01 \\
\hline Total & $\mathbf{8 0 0 3}$ & $\mathbf{1 0 0 , 0 0}$ & $\mathbf{1 3 3 0 7}$ & $\mathbf{1 0 0 , 0 0}$ & $\mathbf{6 6 , 2 8}$ \\
\hline
\end{tabular}

Fonte: Elaboração Própria.

Apesar do debate e divergência acerca da continuidade do processo de desconcentração industrial e/ou tendência à reconcentração da indústria, os resultados da tabela 01 nos sugerem afirmar a continuidade (ainda que em ritmo lento) no processo de deslocamento de indústrias para a Bahia, em especial o interior do seu Estado, em 2004 esta área correspondia a 67,54\% do total de unidades produtivas contra 32,46\% na RMS. Essa participação relativa tende a beneficiar o interior do estado, diminuindo o "gap" entre a capital e demais municípios que integram o estado baiano, uma vez que se observa em 2014 que o interior do Estado lidera participação relativa em número de indústrias $(68,65 \%)$ e a RMS $(31,35 \%)$.

Diante de tal conjuntura, segundo Ferreira e Lemos (2000), as políticas de incentivos fiscais, por si só não garante a permanência efetiva dos estabelecimentos no Estado. Considerando que o capital industrial é volátil e procura regiões que conceda maiores incentivos e/ou menores custos de produção, é necessário incentivar o desenvolvimento regional, o qual deve está articulado com os aspectos locais de cada espaço geográfico.

\section{EVOLUÇÃo do EMPREgo FORMAL POR RAMO DE ATIVIDAdE NA BAHIA}

Os dados da tabela 02 apresentam a evolução do emprego formal por ramo de atividade, em que se destaca a elevada concentração de trabalhadores empregados no setor de serviços, tanto na RMS como no interior do estado baiano. Em 2004, o setor de serviços empregava 69,96\% da mão-de-obra na RMS e reduziu de forma modesta para 65,27\% a sua participação em 2004. Todavia, em termos absolutos, constata-se variação de 40,10\% ao passar de um estoque de 537.173 empregados em 2004 para 752.582 em 2014. No caso da RMS em 2004, o setor de serviços era responsável por 52,63\% das vagas no mercado de trabalho diminuindo para 52,23\% em 2014. Em termos absolutos, o estoque de trabalhadores aumenta de 363.442 em 2004 para 636.983 em 2014, ocasionando variação de 75,26\%. 
Tabela 02 - Evolução do emprego formal por setores de atividade econômica na Região Metropolitana de Salvador e interior do estado-BA, 2004/2014.

\begin{tabular}{c|c|c|c|c|c|c|c|c}
\hline \multirow{2}{*}{ Setores } & \multicolumn{4}{|c|}{ RMS } & \multicolumn{4}{c}{ INTERIOR } \\
\cline { 2 - 9 } & $\mathbf{2 0 0 4}$ & $\mathbf{6}$ & $\mathbf{2 0 1 4}$ & $\mathbf{9}$ & $\mathbf{2 0 0 4}$ & $\mathbf{2}$ & $\mathbf{2 0 1 4}$ & $\mathbf{\%}$ \\
\hline Indústria & $\mathbf{4}$ & 9,03 & 111.837 & 9,70 & 97.118 & 14,06 & 155.679 & 12,76 \\
$\begin{array}{c}\text { Constru- } \\
\text { ção civil }\end{array}$ & 40.540 & 5,28 & 102.454 & 8,89 & 20.634 & 2,99 & 60.746 & 4,98 \\
\hline $\begin{array}{c}\text { Comér- } \\
\text { cio }\end{array}$ & 115.620 & 15,06 & 183.783 & 15,94 & 134.996 & 19,55 & 278.739 & 22,85 \\
$\begin{array}{c}\text { Serviços } \\
\text { Agrope- } \\
\text { cuária }\end{array}$ & 537.173 & 69,96 & 752.582 & 65,27 & 363.442 & 52,63 & 636.983 & 52,23 \\
\hline $\begin{array}{c}\text { Outros/ } \\
\text { ignorado }\end{array}$ & 0 & 0,116 & 2.272 & 0,20 & 74.331 & 10,76 & 87.508 & 7,17 \\
\hline Total & $\mathbf{7 6 7 . 7 9 4}$ & $\mathbf{1 0 0 , 0 0}$ & $\mathbf{1 . 1 5 2 . 9 2 8}$ & $\mathbf{1 0 0 , 0 0}$ & $\mathbf{6 9 0 . 5 2 1}$ & $\mathbf{1 0 0 , 0 0}$ & $\mathbf{1 . 2 1 9 . 6 5 5}$ & $\mathbf{1 0 0 , 0 0}$ \\
\hline
\end{tabular}

Fonte: Elaboração Própria.

Como o foco deste trabalho é analisar a dinâmica econômica do mercado de trabalho industrial formal, observa-se que o setor industrial se configura como o terceiro maior empregador tanto na RMS quanto no interior baiano. Percebe-se um tímido aumento na participação relativa da indústria na RMS na geração de empregos formais ao passar de 9,03\% em 2004 para 9,70\% em 2014, em termos absolutos houve um aumento de 69.345 empregados para 111.837 em 2014, ocasionando variação de 61,28\% (Tabela 02).

O interior baiano apresenta dinâmica um pouco diferenciada em relação à RMS, uma vez, que ocorreu um declínio na participação da indústria formal na geração total de empregos, ao passar de $14.06 \% \mathrm{em}$ 2004 para $12,76 \%$ em 2014. No entanto, em termos absolutos houve aumento no número de empregados ao passar de 97.118 para 155.679, ocasionando variação de 60,30\% entre 2004 e 2014 (Tabela 02).

O setor da construção civil apresentou ranking em termos de crescimento no número de postos formais de trabalho, ao passar de 5,28\% para 8,89\% entre 2004 e 2014 na RMS, o que implica variação de $152,72 \%$ ao passar em termos absolutos de 40.540 para 102.454 no período analisado. Para o interior baiano, a dinâmica é semelhante ao observar que a participação passa de $2,99 \%$ para 4,98\% no período em análise, em números absolutos, estes passam de 20.634 para 60.746 empregados, ocasionando variação de 194,40\% (Tabela 02).

O desempenho favorável na evolução do emprego formal para o setor da construção civil deve ao estímulo do governo federal ao investimento produtivo através das ações do Programa de Aceleração do Crescimento (PAC), Programas habitacionais, dentre outros (SILVA FILHO; QUEIROZ, 2014). Por outro lado o aumento na instalação de indústrias de transformação, mediante desconcentração produtiva (tendência observada na tabela 02) na Bahia favorece o setor da construção civil mediante disponibilização de insumos necessários para expansão da capacidade produtiva.

Para o setor agropecuário, como estamos considerando apenas o emprego formal, percebe-se queda tanto em termos absolutos quanto relativos na RMS e no Interior baiano. Segundo Graziano da Silva (1998), esse desempenho é reflexo da mecanização agrícola, em que, ao passo que eleva a produtividade marginal do trabalho, contribui para a queda no número de empregos formais no campo. 


\section{EVOLUÇÃo DO EMPREgo FORMAL DA INDÚSTRIA BAIANA}

No tocante ao número de empregos na indústria de transformação, os dados da Tabela 03 revelam que em 2004, na RMS, a indústria química é a que mais empregava trabalhadores $24,21 \%$ com queda para $18,76 \%$ em 2014, sendo o ramo de atividade que mais emprega na RMS nos anos em estudo.

No interior, esse tipo de indústria não tem a mesma dinâmica no processo de geração de empregos, mesmo apresentando leve aumento, ao passar de 5,21\% empregos no interior em 2004 para 6,06\% em 2014. Evidencia-se que a indústria de produtos alimentícios, bebidas e álcool etílico apresentaram significativo número de trabalhadores empregados na RMS quanto no interior, com destaque para o aumento em termos absolutos e relativos evidenciados em todo o Estado, no período em análise (Tabela 03).

Em 2004 a RMS tinha 16,10\% da mão-de-obra formal empregada nessa atividade, passando em 2014 para 18,49\%. No interior do Estado o aumento percentual passou de 21,36\% em 2004 para 22,01\% em 2014 (Tabela 03).

Tabela 03 - Evolução do emprego formal na indústria formal na Região Metropolitana de Salvador e Interior do Estado-BA, 2004/2014.

\begin{tabular}{|c|c|c|c|c|c|c|c|c|}
\hline \multirow[b]{2}{*}{ Ramo de Atividade } & \multicolumn{4}{|c|}{ RMS } & \multicolumn{4}{|c|}{ INTERIOR } \\
\hline & 2004 & $\%$ & 2014 & $\%$ & 2004 & $\%$ & 2014 & $\%$ \\
\hline Extrativa Mineral & 1.104 & 1,59 & 3.898 & 3,49 & 7.623 & 7,85 & 12.538 & 8,05 \\
\hline $\begin{array}{l}\text { Indústria de prod. Mi- } \\
\text { nerais não met. }\end{array}$ & 2.685 & 3,87 & 6.126 & 5,48 & 7.611 & 7,84 & 14.524 & 9,33 \\
\hline Indústria metalúrgica & 4.764 & 6,87 & 8.512 & 7,61 & 3.788 & 3,90 & 7.923 & 5,09 \\
\hline Indústria mecânica & 3.702 & 5,34 & 4.758 & 4,25 & 2.026 & 2,09 & 5.614 & 3,61 \\
\hline $\begin{array}{l}\text { Ind material .elét e de } \\
\text { comunicações }\end{array}$ & 1.109 & 1,60 & 1.823 & 1,63 & 1.460 & 1,50 & 1.735 & 1,11 \\
\hline Ind.transporte & 5.599 & 8,07 & 9.221 & 8,24 & 492 & 0,51 & 2.232 & 1,43 \\
\hline Ind.madeira & 1.755 & 2,54 & 3.914 & 3,49 & 3.945 & 4,06 & 6.336 & 4,07 \\
\hline Ind.papelão & 3.161 & 4,56 & 5.255 & 4,70 & 3.556 & 3,67 & 7.099 & 4,56 \\
\hline Ind.borracha,fumo & 1.433 & 2,07 & 4.491 & 4,02 & 6.296 & 6,48 & 8.277 & 5,32 \\
\hline Ind.química & 16.790 & 24,21 & 20.976 & 18,76 & 5.064 & 5,21 & 9.429 & 6,06 \\
\hline Ind.têxtil & 6.039 & 8,71 & 6.915 & 6,18 & 9.756 & 10,04 & 15.301 & 9,83 \\
\hline Ind. de calçados & 334 & 0,48 & 196 & 0,18 & 19.447 & 20,02 & 23.972 & 15,40 \\
\hline Ind.prod.alimentício & 11.168 & 16,10 & 20.677 & 18,49 & 20.749 & 21,36 & 34.260 & 22,01 \\
\hline $\begin{array}{l}\text { Serviços ind. de utili- } \\
\text { dade pública }\end{array}$ & 9.682 & 13,96 & 15.075 & 13,48 & 5.325 & 5,48 & 6.439 & 4,14 \\
\hline Total & 69345 & 100,00 & 111.837 & 100,00 & 97.138 & 100,00 & 155.679 & 100,00 \\
\hline
\end{tabular}

Fonte: Elaboração Própria.

O expressivo aumento no número de postos de trabalho para a indústria alimentícia ${ }^{2}$ no Estado baiano não segue uma relação direta com os ganhos de massa salarial auferidos no período pós-estabilização, bem como as políticas recorrentes de valorização real do salário mínimo, uma vez que segundo Hague-

\footnotetext{
${ }^{2} \mathrm{O}$ aumento da participação deste setor está relacionado à expansão da fronteira agrícola, uma vez que trata da desconcentração de bens ligados a produção de gêneros primários.
} 


\section{Moura \& Paiva}

nauer et al (2001), a demanda por alimentos é relativamente elástica com a expansão da renda, o que sustenta o nível de produção mesmo quando os rendimentos tendem a arrefecer.

A explicação coerente é que a indústria de alimentos encontrou no Estado baiano um cenário ideal para a reprodução do capital, através dos incentivos ficais e financeiros, mão-de-obra barata. O aumento dos postos formais de trabalho não tem relação direta com aumento da massa salarial e demanda por alimentos, pois segundo Sandroni (2003), conforme a teoria microeconômica de Engel a demanda por alimentos é relativamente inelástica, ou seja, mesmo que os rendimentos oscilem a produção de alimentos continua estável.

Dessa forma, fica evidente que a indústria baiana ainda se apresenta participação significante em torno de segmentos marcados por processos produtivos intensivos em capital (indústria química, extrativa mineral, indústria de minerais não-metálicos e indústria metalúrgica), especializados na fabricação de bens intermediários, destinados, em grande parte a abastecer os mercados das regiões mais dinâmicas do país, como a região Sudeste.

No que tange à indústria calçadista no interior do estado no período 2004/2014 houve uma queda em termos relativos passando de $20,02 \%$ para $15,40 \%$ do total de empregados, mesmo com tal redução esse setor é o segundo que mais emprega no Interior ocupando em 2014, 23.972 postos formais de trabalho. (Tabela 03).

No que tange aos ocupados em setores intensivos em tecnologia, dois setores estratégicos são analisados: indústria do material elétrico e de comunicações e indústria de material de transporte. Os resultados são antagônicos no território baiano, uma vez que o primeiro setor participa na RMS em 2004 com 1,60\% do total de ocupados formais aumentando para 1,63\% em 2014. No caso do Interior baiano percebe-se uma queda percentual de $1,50 \%$ em $1,11 \%$ no decorrer do período estudado. Para o setor de material de transporte em 2004 estavam ocupados 8,07\% na RMS vindo a cair à participação relativa para 8,24\% em 2014. Para o Interior do Estado percebe-se um aumento passando de empregados formais passando de $0,51 \%$ para $1,43 \%$ em apenas dez anos. (Tabela 03 ).

Resultados empíricos mostram que os setores intensivos em tecnologia no Estado ampliaram o número de ocupados formais ao longo do decênio analisado. No caso do setor de material de transporte a oferta de vagas se ampliou para a RMS, enquanto que o material de transporte alocou seus postos de trabalho preferencialmente a mão-de-obra interiorana, tal movimento contraria a ideia de Cano (1997), ao observar que as regiões periféricas por motivos estruturais assim como pela divisão inter-regional do trabalho elencaria a estrutura produtiva em setores trabalho/intensivos enquanto que aqueles que possuem maior conteúdo tecnológico se reconcentrariam especialmente para a metrópole paulista.

Os resultados vão ao encontro da tese de Pacheco (1998), ao afirmar que os impactos diferenciados da crise da dívida externa, desemprego em áreas de elevada densidade industrial especialmente pósestabilização seriam fatores decisivos para alocação dos investimentos industriais (mesmo de forma seletiva) em favor de espaços que ofereçam maiores vantagens competitivas de custos, disseminado "ilhas de produtividade" em meio a áreas periféricas.

\section{TAMANHO DO ESTABELECIMENTO DA INDÚSTRIA FORMAL BAIANA}

Conforme a tabela 04, que apresenta o número de empregados formais segundo porte do estabelecimento industrial, observa-se que na RMS em 2004, 24,09\% do total de trabalhadores formais na indústria estavam ocupados em empresas de grande porte, essa participação relativa tende a se elevar para 32,09\% em 2014. Para o Interior baiano 29,33\% dos trabalhadores formais estavam ocupados na indústria de grande porte em 2004 passam de 29,33\% em 2004 vindo a aumentar para 31,42\% em 2014. 
No caso da participação da média indústria, percebe-se que tanto na RMS quanto no Interior do Estado uma queda relativa no número de empregados. Na RMS eles passam da primeira colocação em volume de emprego (37,33\%) em 2004 para o segundo lugar (31,23\%) em 2014. No Interior sai da segunda posição $(26,35 \%)$ e reduz para a quarta colocação $(23,51 \%)$ (Tabela 04$)$.

Para às micro e pequenas empresas industriais (MPE) em $2004(38,58 \%)$ dos empregados estavam ocupados nesse porte de empresa vindo a cair para 36,88\% no período em análise para a RMS. No caso do Interior baiano a proporção relativa de empregados em micro e pequenas indústrias passam de 44,32\% em 2004 para 45,07\% em 2014 (Tabela 04).

Tabela 04 - Distribuição do emprego formal na indústria, por porte na Região Metropolitana de Salvador e Interior do Estado-BA, 2004/2014.

\begin{tabular}{c|c|c|c|c|c|c|c|c}
\hline $\begin{array}{c}\text { Número de empregados por } \\
\text { porte da indústria }\end{array}$ & \multicolumn{4}{|c|}{ RMS } & \multicolumn{3}{c}{ INTERIOR } & \\
\cline { 2 - 9 } & $\mathbf{2 0 0 4}$ & $\mathbf{\%}$ & $\mathbf{2 0 1 4}$ & $\mathbf{0}$ & $\mathbf{2 0 0 4}$ & $\mathbf{\%}$ & $\mathbf{2 0 1 4}$ & $\mathbf{\%}$ \\
\hline Micro (1 a 19) & 10.316 & 14,88 & 16.154 & 14,44 & 21.247 & 21,88 & 33.263 & 21,37 \\
\hline Pequena (20 a 99) & 16.435 & 23,70 & 24.869 & 22,24 & 21.795 & 22,44 & 36.896 & 23,70 \\
\hline Média (100 a 499) & 25.889 & 37,33 & 34.926 & 31,23 & 25.592 & 26,35 & 36.606 & 23,51 \\
\hline Grande (500 ou mais) & 16.705 & 24,09 & 35.888 & 32,09 & 28.484 & 29,33 & 48.919 & 31,42 \\
\hline Total & $\mathbf{6 9 . 3 4 5}$ & $\mathbf{1 0 0 , 0 0}$ & $\mathbf{1 1 1 . 8 3 7}$ & $\mathbf{1 0 0 , 0 0}$ & $\mathbf{9 7 . 1 1 8}$ & $\mathbf{1 0 0 , 0 0}$ & $\mathbf{1 5 5 . 6 7 9}$ & $\mathbf{1 0 0 , 0 0}$ \\
\hline
\end{tabular}

Fonte: Elaboração Própria.

\section{NÚMEROS DOS TRABALHADORES FORMAIS BAIANOS SEGUNDO SEXO}

A análise desagregada por sexo mostra que em 2004 havia 69.345 trabalhadores empregados na indústria formal na RMS, sendo que 74,84\% são do sexo masculino e 25,16\% do sexo feminino. Em 2014 a participação de homens cai levemente para 74,19\% e das mulheres aumenta para 25,81\%. O interior baiano contava em 2004 com um total de 97.118 trabalhadores no setor industrial, dos quais 72,09\% são do sexo masculino contra 27,91\% do sexo feminino, e em 2014 tem movimento diferenciado da RMS, ao aumento, mesmo de forma tímida, na participação do sexo masculino (72,25\%) e feminino (27,75\%). (Tabela 05).

Apesar do crescimento do número de empregos na indústria formal no período em estudo, em 2014 prevalece a grande concentração de trabalhadores do sexo masculino (72,19\% na RMS e 72,25\% no Interior da Bahia) (Tabela 05).

Verifica-se, portanto, que durante o decênio em análise (2004/2014) houve avanços continuidade dos avanços femininos, ainda lentamente na RMS que aumentou em termos relativos à participação feminina na atividade industrial, corroborando Brito (2007), no qual afirma que o ingresso crescente da mulher no mercado de trabalho está concernente à redução da taxa de fecundidade, mudança na estrutura familiar e maior acesso à escolaridade formal. 
Tabela 05 - Número de empregados na indústria formal, segundo sexo na Região Metropolitana de Salvador e Interior do Estado-BA-2004/2014.

\begin{tabular}{cccccccccc}
\hline \multirow{2}{*}{ Sexo } & \multicolumn{4}{c}{ RMS } & \multicolumn{4}{c}{ INTERIOR } \\
\cline { 2 - 10 } & $\mathbf{2 0 0 4}$ & $\mathbf{0}$ & $\mathbf{2 0 1 4}$ & $\mathbf{\%}$ & $\mathbf{2 0 0 4}$ & $\mathbf{\%}$ & $\mathbf{2 0 1 4}$ & $\mathbf{\%}$ \\
\hline Masculino & 51.895 & 74,84 & 82.977 & 74,19 & 70.014 & 72,09 & 112.485 & 72,25 \\
Feminino & 17.450 & 25,16 & 28.860 & 25,81 & 27.104 & 27,91 & 43.194 & 27,75 & $\mathbf{1 0 0 , 0 0}$ \\
\hline Total & $\mathbf{6 9 . 3 4 5}$ & $\mathbf{1 0 0 , 0 0}$ & $\mathbf{1 1 1 . 8 3 7}$ & $\mathbf{1 0 0 , 0 0}$ & $\mathbf{9 7 . 1 1 8}$ & $\mathbf{1 0 0 , 0 0}$ & $\mathbf{1 5 5 . 6 7 9}$ & \\
\hline
\end{tabular}

Fonte: Elaboração Própria.

\section{ESCOLARIDADE DOS TRABALHADORES FORMAIS BAIANO}

Com relação ao nível de escolaridade, chama atenção o elevado percentual de trabalhadores na indústria formal com poucos anos de estudo (Tabela 06) notadamente no Interior do Estado da Bahia, dos quais $37,49 \%$ dos trabalhadores formais em 2004 tinham apenas o ensino fundamental incompleto contra $19,15 \%$ na RMS.

Em 2014, a indústria na RMS apresentou declínio em termos percentuais na participação de trabalhadores que tinham até o ensino fundamental incompleto, ao passar de 19,15\% em 2004 para 9,08\% em 2014. Em termos absolutos, isso representa uma variação negativa de 30,75\% com queda de 13.278 empregados em 2004 para 10.155 em 2014. Tal movimento indica a substituição de trabalhadores menos escolarizados por aqueles mais especializados, devido novos métodos de organização da produção e do trabalho (Tabela 06).

Todavia, no Interior baiano apresentou declínio no número de trabalhadores com nível de escolaridade até o ensino fundamental incompleto, de 37,49\% em 2004 para 18,51\% em 2014. Em termos absolutos, assim como na RMS, verifica-se queda do número desses trabalhadores que passou de 36.409 para 28.815 no período analisado, sofrendo variação negativa de $26.35 \%$. (Tabela 06).

A diminuição no número de trabalhadores menos escolarizados na indústria formal na Bahia foi em parte acompanhada pelo aumento na quantidade daqueles mais anos de escolaridade. Em 2014 a RMS empregam em maior número $(63,17 \%)$ trabalhadores com ensino médio completo até superior incompleto. No Interior do Estado da Bahia a dinâmica é semelhante ao observar ampliação na contratação de trabalhadores com ensino médio completo até superior incompleto de 31,89\% em 2004 para 55,94\%, indicando que na Bahia existe seletividade na contratação da mão-de-obra (Tabela 06).

Trabalhadores com ensino superior completo apresentaram aumentos significativos, na RMS eles passam de 9,81\% para 15,79\% no período analisado, contra 2,29\% em 2004 para 5,25\% em 2014, tendência esta verificada no interior do Estado. Tal resultado segundo Pereira (2004) vai ao encontro do modelo Toyotismo de produção que se caracteriza pela inovação, flexibilidade dos trabalhadores, apropriando-se da dimensão intelectual da mão-de-obra, em substituição dos modelos rígidos do taylorismo e fordismo (ANTUNES, 2005). 
Tabela 06 - Total de empregados na indústria formal, segundo grau de instrução na Região Metropolitana de Salvador e Interior do Estado-BA- 2004/2014.

\begin{tabular}{|c|c|c|c|c|c|c|c|c|}
\hline \multirow{2}{*}{$\begin{array}{l}\text { Nível de escola- } \\
\text { ridade }\end{array}$} & & \multirow{2}{*}{$\begin{array}{c}\text { RMS } \\
\%\end{array}$} & \multirow[b]{2}{*}{2014} & \multirow[b]{2}{*}{$\%$} & \multicolumn{4}{|c|}{ INTERIOR } \\
\hline & 2004 & & & & 2004 & $\%$ & 2014 & $\%$ \\
\hline $\begin{array}{l}\text { Sem instrução até } \\
\text { fund. incomp. }\end{array}$ & 13.278 & 19,15 & 10.155 & 9,08 & 36.409 & 37,49 & 28.815 & 18,51 \\
\hline $\begin{array}{l}\text { Fund.comp. até } \\
\text { méd. inc }\end{array}$ & 13.801 & 19,90 & 13.384 & 11,97 & 27.515 & 28,33 & 31.615 & 20,31 \\
\hline $\begin{array}{l}\text { Médio comp. Até } \\
\text { sup.inc. }\end{array}$ & 35.460 & 51,14 & 70.644 & 63,17 & 30973 & 31,89 & 87.082 & 55,94 \\
\hline $\begin{array}{l}\text { Superior com- } \\
\text { pleto }\end{array}$ & 6.806 & 9,81 & 17.654 & 15,79 & 2.221 & 2,29 & 8.167 & 5,25 \\
\hline Total & 69345 & 100,00 & 111.837 & 100,00 & 97.118 & 100,00 & 155.679 & 100,00 \\
\hline
\end{tabular}

Fonte: Elaboração Própria.

\section{Tempo de Serviço dos Trabalhadores baianos}

Em relação ao tempo de permanência dos trabalhadores empregados na indústria formal. Em 2004, 29,09\% ficaram empregados por menos de 01 ano na RMS diminuindo levemente para 27,92\% em 2014, e no Interior da Bahia eles passam de 35,61\% em 2004 para 29,91\% em 2014 (Tabela 07). Apesar do elevado nível de rotatividade no Estado baiano em estudo, novamente os empregados no Interior do Estado estão mais suscetíveis ao desemprego do que na RMS.

A elevada concentração de trabalhadores com pouco tempo de serviço na indústria formal baiana decorre provavelmente do processo de reestruturação produtiva aliada aos novos métodos de organização da produção e do trabalho, em que um cenário de inserção neoliberal na estrutura produtiva, se torna mais rentável para os empregadores utilizarem mão-de-obra terceirizada para aliviar os elevados encargos trabalhistas sobre a folha de pagamento com objetivo de reduzir custos (POCHMANN, 1999; PEREIRA, 2004; BALTAR, 2003).

Em relação aos empregados a mais de 05 anos na indústria formal na RMS, em 2004 registrou a maior parte $32,31 \%$, vindo a cair para 30,27\% em 2014. No caso do Interior baiano eles passam do segundo lugar na proporção de ocupados com 19,94\% em 2004 para 24,62\% em 2014. Esse resultado indica que os trabalhadores do Interior baiano estão mais vulneráveis a rotatividade, em que mesmo diante dos modestos avanços na estabilização do emprego formal, ainda há predominância da precarização bem como a instabilidade no mercado de trabalho brasileiro (Tabela 07). 
Tabela 07 - Distribuição dos trabalhadores na indústria formal, segundo tempo de serviço na Região Metropolitana de Salvador e Interior do Estado-BA-2004/2014.

\begin{tabular}{c|c|c|c|c|c|c|c|c}
\hline \multirow{2}{*}{$\begin{array}{c}\text { Tempo de ser- } \\
\text { viço }\end{array}$} & \multicolumn{7}{|c|}{ RMS } & \multicolumn{2}{c}{ INTERIOR } \\
\cline { 2 - 9 } & $\mathbf{2 0 0 4}$ & $\mathbf{2 0 1 4}$ & $\mathbf{2}$ & $\mathbf{2 0 0 4}$ & $\mathbf{\%}$ & $\mathbf{2 0 1 4}$ & $\%$ \\
\hline $\begin{array}{c}\text { Menos de } 01 \\
\text { ano }\end{array}$ & 20.169 & 29,09 & 31.225 & 27,92 & 34.585 & 35,61 & 45.470 & 29,91 \\
\hline $\begin{array}{c}01 \text { a menos de } \\
03 \text { anos }\end{array}$ & 18.207 & 26,26 & 30.071 & 26,89 & 28.800 & 29,65 & 46.151 & 29,64 \\
\hline $\begin{array}{c}03 \text { a menos de } \\
05 \text { anos }\end{array}$ & 8.559 & 12,34 & 16.675 & 14,91 & 14.360 & 14,79 & 25.706 & 16,51 \\
\hline 05 ou mais anos & 22.405 & 32,31 & 33.849 & 30,27 & 19.367 & 19,94 & 38.333 & 24,62 \\
\hline Ignorado & 05 & 0,01 & 17 & 0,01 & 06 & 0,05 & 19 & 0,01 \\
\hline Total & $\mathbf{6 9 . 3 4 5}$ & $\mathbf{1 0 0 , 0 0}$ & $\mathbf{1 1 1 . 8 3 7}$ & $\mathbf{1 0 0 , 0 0}$ & $\mathbf{9 7 . 1 1 8}$ & $\mathbf{1 0 0 , 0 0}$ & $\mathbf{1 5 5 . 6 7 9}$ & $\mathbf{1 0 0 , 0 0}$ \\
\hline
\end{tabular}

Fonte: Elaboração Própria.

\section{REMUNERAÇÃo DOS TRABALHADORES BAIANOS}

Sob a ótica da remuneração (Tabela 08) destaca-se na RMS e no Interior do Estado baiano empobrecimento dos trabalhadores no período em estudo, tanto pelo aumento na proporção daqueles que recebiam mais de 01 a 03 salários mínimos quanto pela redução dos que estavam localizados nas faixas superiores de rendimento.

Em 2014, a precarização aumenta na RMS e no Interior baiano. O percentual dos trabalhadores que ganhavam até 03 salários mínimos amplia-se significativamente de 49,46\% na RMS em 2004 para 58,61\% em 2014 e no Interior do Estado passa de 78,59\% em 2004 para 80,3 (ressalta-se o declínio na participação de empregados no Interior do Estado passando de 16,36\% para 10,74\% no período em estudo). A baixa remuneração da mão-de-obra desse Estado sem dúvida foi um dos atrativos para a abertura de novos postos formais de trabalho em indústrias intensivas em mão-de-obra, a exemplo da alimentícia. (Tabela 08).

Para os ocupados formais na indústria formal na faixa de até 01 salário mínimo, as posições são antagônicas no espaço geográfico analisado, enquanto a RMS amplia de forma tímida a participação relativa dos empregados formais situados nessa faixa salarial, saltando de 3,29\% em 2004 para 3,90\% em 2014, por outro lado o interior baiano reduz de forma significativa a participação desses ocupados passando de 16,36\% em 2004 para 10,74\% em 2014 (Tabela 08).

Para aqueles que ganhavam acima de 05 salários mínimos houve significativa redução na proporção de trabalhadores concentrados nessas faixas de rendimento tanto na RMS quanto no interior baiano, sendo mais intensa para a mão-de-obra formal empregada na indústria formal interiorana. (Tabela 08).

Na RMS, em 2004, ganhavam acima de 05 salários mínimos 33,55\% caindo para 23,01\% em 2014, e no interior baiano eles passam de $11,19 \%$ para 8,08\% em 2014. Em suma, em 2014 pouco mais de 8,08\% dos empregados formais no interior da Bahia recebiam acima de 05 salários mínimos e aproximadamente um quarto $(23,01 \%)$ dos empregados na RMS localizavam acima de 05 salários mínimos, apontando novamente diferenciação da estrutura dos salários no Estado analisado (Tabela 08).

Na RMS em 2004, 38,6\% da mão-de-obra empregada na indústria formal concentravam-se nas faixas de 01 a 05 salários mínimos vindos a aumentar para 41,8\% em 2014. Em termos absolutos destaca um 
aumento de 26.766 para 46.746 no período estudado implicando variação de $74,65 \%$. No caso do Interior do Estado 44,44\% dos trabalhadores formais empregados em 2004 situavam nas faixas de 01 a 05 salários mínimos, registrando em 2014 um tímido aumento passando para 46,15\% do total de trabalhadores. Em termos absolutos tem-se a passagem de 43.160 empregados formais para em 2004 no interior baiano para 71.857 trabalhadores, implicando variação de 66,49\% (Tabela 08).

Essa ótica torna-se conflitante, dado que os trabalhadores da Bahia melhoraram sua qualificação ao longo dos 10 anos em análise e os resultados empíricos apontam redução no nível de rendimento dos trabalhadores ${ }^{3}$, que pode ser explicado pela queda dos rendimentos do trabalho no produto da economia em um cenário de elevada precarização nas relações assalariadas no mercado de trabalho.

Percebe-se, portanto, uma melhor distribuição de renda no Estado, sendo que a renda global do trabalho situada nas faixas inferiores (mais de 01 a $05 \mathrm{SM}$ ) que de fato sinaliza que a política de valorização do salário mínimo garantiu aos trabalhadores que migraram das faixas mais elevadas de salário para as mais baixas, elevação do poder de compra ${ }^{4}$ e relativa amenização das políticas de caráter neoliberal adotadas desde os anos 1990, não combatendo o problema estrutural da precarização do mercado de trabalho que é elevada rotatividade que funciona como Proxy para elevação dos rendimentos nominais.

Tabela 08 - Total de empregados na indústria formal, segundo faixa de remuneração na Região Metropolitana de Salvador e Interior do Estado-BA-2004/2014.

\begin{tabular}{c|c|c|c|c|c|c|c|c}
\hline \multirow{2}{*}{$\begin{array}{c}\text { Faixa média de } \\
\text { rendimento em } \\
(\text { SM })\end{array}$} & \multicolumn{2}{|c|}{ RMS } & \multicolumn{2}{c|}{} & \multicolumn{3}{c}{ INTERIOR } & \\
\cline { 2 - 9 } & $\mathbf{2 0 0 4}$ & $\mathbf{\%}$ & $\mathbf{2 0 1 4}$ & $\mathbf{\%}$ & $\mathbf{2 0 0 4}$ & $\mathbf{\%}$ & $\mathbf{2 0 1 4}$ & $\mathbf{\%}$ \\
\hline Até 01 salário & 2.287 & 3,29 & 4.364 & 3,90 & 15.889 & 16,36 & 16.722 & 10,74 \\
\hline Mais de 01 a 02 SM & 23.351 & 33,67 & 44.305 & 39,62 & 50.703 & 52,21 & 90.696 & 58,26 \\
\hline Mais de 02 a03 SM & 8.671 & 12,50 & 16.875 & 15,09 & 9.730 & 10,02 & 17.595 & 11,30 \\
\hline Mais de 03 a 05 SM & 10.372 & 14,96 & 16.668 & 14,90 & 7.154 & 7,37 & 12.333 & 7,92 \\
\hline Mais de 05 a 10 SM & 10.658 & 15,37 & 13.738 & 12,28 & 6.150 & 6,33 & 7.669 & 4,93 \\
\hline Mais de 10 a 20 SM & 6.857 & 9,89 & 7.648 & 6,84 & 3.088 & 3,18 & 3.396 & 2,18 \\
\hline Mais de 20 SM & 5.748 & 8,29 & 4.355 & 3,89 & 1.636 & 1,68 & 1.503 & 0,97 \\
\hline Sem declaração & 1.401 & 2,02 & 3.884 & 3,47 & 2.768 & 2,85 & 5.765 & 3,70 \\
\hline Total & $\mathbf{6 9 . 3 4 5}$ & $\mathbf{1 0 0 , 0 0}$ & $\mathbf{1 1 1 . 8 3 7}$ & $\mathbf{1 0 0 , 0 0}$ & $\mathbf{9 7 . 1 1 8}$ & $\mathbf{1 0 0 , 0 0}$ & $\mathbf{1 5 5 . 6 7 9}$ & $\mathbf{1 0 0 , 0 0}$ \\
\hline
\end{tabular}

Fonte: Elaboração Própria.

\section{CONSIDERAÇões FINAIS}

Conclui-se que a desconcentração industrial no território baiano impactou fortemente no emprego formal desse estado, entre os anos de 2004 e 2014, sendo que o Interior do Estado da Bahia aumentou $69,01 \%$ do volume de investimentos industriais contra 60,59\% na RMS.

\footnotetext{
${ }^{3}$ Os resultados obtidos parecem contrariar a teoria do capital humano que segundo Sandroni (2003) afirma que os indivíduos mais escolarizados obtêm retornos financeiros mais elevados, em virtude da aquisição em educação proporcionar elevação da renda do indivíduo, o que eleva a produtividade e age como um processo de elevação para o mercado de trabalho.

${ }^{4}$ Deve-se afirmar que inicialmente com o Plano Real e posteriormente com a política de valorização do salário mínimo ampliaram o poder de compra dos rendimentos do trabalho e amenizaram relativamente às consequências do modelo neoliberal ajustado no mercado de trabalho brasileiro, uma vez que os trabalhadores formais situados nas primeiras faixas de rendimento, tendência essa que se amplia com grande magnitude a partir do pós-década de 1990 (DEDECCA, 1998; POCHMANN, 2001).
} 
No tocante ao perfil sociodemográfico, 74,19\% dos trabalhadores são do sexo masculino na RMS contra $72,25 \%$ no Interior do Estado em 2014, sendo alocados predominantemente em empreendimentos de médio e grande porte.

Apesar do setor industrial não ser, de maior destaque na geração de empregos formais na Unidade Federativa em estudo, se percebe maior participação relativa de ocupados nos setores da indústria, sendo que predominam em 2014, os empregados na indústria química $(18,76 \%)$ na RMS e na indústria alimentícia $(22,01 \%)$ no Interior da Bahia, indicando que os municípios fora da região metropolitana são sedutores na atração de empresas em trabalho/intensivas enquanto que Salvador e seus municípios ao redor atraem segmentos mais capital/intensivo.

Predomina em 2014 tanto na RMS (63,17\%), quanto no interior $(55,94 \%)$ seletividade na contratação de empregados formais com ensino médio completo até superior incompleto em relações assalariadas marcadas por alta rotatividade, decorrente em parte da terceirização da produção e dos novos métodos de organização do trabalho no bojo das políticas neoliberais.

No tocante a variável renda se percebe um empobrecimento dos trabalhadores formais que migraram das faixas de rendimento mais elevadas para as mais baixas, sendo que o Interior baiano a precarização é mais intensa, ocorrendo ao longo dos anos um maior "gap" entre nível de escolaridade e rendimentos do trabalho.

Em síntese, ocorreu ao longo do período em estudo no estado baiano uma diminuição das desigualdades socioeconômicas, uma vez que os rendimentos/salários tenderam ao arrefecimento tanto no Interior quanto na RMS, em um quadro de intensa seletividade por sexo, grau de instrução, tempo de serviço e faixa de remuneração.

\section{REFERÊNCIAS}

ANTUNES, R. Adeus ao trabalho?: Ensaios sobre a as metamorfoses e a centralidade do mundo do trabalho. 10 ed. São Paulo: Cortez, 2005.

ARAÚJO, J. B. Mercado de trabalho e desigualdade: o Nordeste brasileiro nos anos 2000, Campinas, 2017, 319 p. Tese (Doutorado em Desenvolvimento Econômico)-Universidade Estadual de Campinas, 2017.

ARRAIS, A. K. M; QUEIROZ, S. N.; ALVES, C. L. B. Mercado de trabalho formal na indústria: comparativo entre as regiões Nordeste e Sudeste nos anos de 1994 e 2004. In: ENCONTRO INTERNACIONAL TRABALHO E FORMAÇÃO DE TRABALHADORES.,2, 2008, Fortaleza. Anais... Fortaleza: LABOR/ UFC, 2008. p. 73-92.

BALTAR, P. E. de A. Estrutura econômica e emprego urbano na década de 1990. In: PRONI, M. W.; HENRIQUE, W. (Org.)Trabalho, mercado e sociedade: o Brasil nos anos. São Paulo: UNESP, 2003, p.107-152.

BARBOSA, M. N. F. A evolução do emprego formal industrial nas cidades médias do Estado do Ceará (Juazeiro do Norte, Crato, Sobral) no período de 1990 a 2010. Natal, RN, 2013, 113 f. Dissertação de (Mestrado em Economia Regional) -Universidade Federal do Rio Grande do Norte (UFRN).

BRANDÃO, D. D. As reconfigurações industriais das regiões metropolitanas do Nordeste: uma análise 
do emprego formal. Natal, RN, 2013, 165f. Dissertação (Mestrado em Economia Regional)-Universidade Federal do Rio Grande do Norte (UFRN), 2013

BRITO, F. A transição demográfica no Brasil: as possibilidades e os desafios para a economia e a sociedade, Minas Gerais: Cedeplar, 2007 (Textos para Discussão, 318).

CANO, W. Concentração e desconcentração industrial no Brasil: 1970/95. Revista econômica e sociedade. São Paulo, n.8, p. 101-141, jun.1997.

CANO, W. Ensaios sobre a crise urbana no Brasil. Campinas: UNICAMP, 2011.

CAVALCANTE, L. H. M. T. Economia baiana: configuração espacial e desenvolvimento recente. Revista Econômica do Nordeste, Fortaleza, v. 35, n01, jan- mar, 2004.

DEDECCA, C. S. Reestruturação e tendência de emprego. In: OLIVEIRA, M. A. Marco (Org). Economia e trabalho, Campinas: Unicamp, 1998.p. 163-185.

FERREIRA, M. F. S; LEMOS, M. B. Localização industrial e fatos estilizados da nova reconfiguração espacial do Nordeste. Revista Econômica do Nordeste, Fortaleza, v.31, n. especial p.484-507, nov., 2000.

FREITAS, M. C. de. Para uma sociologia histórica da infância no Brasil. In: ,História social da infância no Brasil. São Paulo: Cortez, 2001. p. 11- 18.

GIL, A. C. Como elaborar projetos de pesquisa. 5.ed. São Paulo: Atlas, 2010.

GRAZIANO DA SILVA, J. A nova dinâmica da agricultura brasileira. 2 ed. Campinas, SP, Unicamp, 1998.

HAGUENAUER, L. et al. Evolução das cadeias produtivas brasileiras na década de 90. Brasília: IPEA, 2001 (Texto para discussão n 786).

IBGE. - Instituto Brasileiro de Geografia e Estatística. Microdados do Censo Demográfico de 2010. 2010. Disponível em: Acesso em: 05 jun de 2017.

LIMA, J. P. R. Traços gerais do desenvolvimento recente da economia do Nordeste. Revista Econômica do Nordeste, Fortaleza, v. 36, n 1, jan-mar. 2005.

MTE- Ministério do Trabalho e Emprego. Disponível em: http://www.rais.gov.br/sitio/index.jsf. Acesso em: dez 2016.

PACHECO, C. A. Fragmentação da nação. Campinas: Unicamp, 1998.

PEREIRA, W. E. N. Evolução do emprego formal nas indústrias das metrópoles nordestinas (1994/2004). Nexos econômicos, v. 10, p. 80-116, 2016.

PEREIRA, J. da S. Dinâmica do emprego formal industrial: comparativo entre a Bahia e o Ceará 
- (1996/2006). Crato-CE. 2008, 86f. (Trabalho de Conclusão de Curso) - Graduação em Ciências Econômicas. Universidade Regional do Cariri- URCA

PEREIRA, G. dos S. As transformações e precarização no mundo do trabalho. Revista de Iniciação Científica da Faculdade de Filosofia e Ciências. São Paulo: Unesp, v.4, n.2, 2004. p. 23-46

POCHMANN, M. O Emprego na Globalização: a nova divisão internacional do trabalho e os caminhos que o Brasil escolheu. São Paulo: Boitempo, 2001.

POCHMANN, M. O trabalho sob fogo cruzado: exclusão, desemprego e precarização no final do século. São Paulo: contexto, 1999.

SANDRONI, P. Novíssimo dicionário de economia. 12. ed. São Paulo: Best Seller, 2003.

SILVA FILHO, L. A; QUEIROZ, S . N. de. A trajetória da Indústria e do Emprego formal no Ceará 1996/2006. ENCONTRO NACIONAL DE ESTUDOS DO TRABALHO., 11. Campinas. Anais... Campinas:ABET, 2009.

SILVA FILHO, L. A. da; QUEIROZ, S. N. de. Errantes do século XXI: de construtores a vítimas do trabalho precário. Revista de Economia. v, 40, n.1, p.165-190, jan/abr, 2014. 